\title{
Cerrahi Hemşireliği Alanında Giyilebilir Teknoloji Kullanımı
}

\author{
Nergis DURSUN*, Emel YILMAZ**
}

\begin{abstract}
$\ddot{O} \mathbf{z}$
İngiltere'de onsekizinci yüzyılın ikinci yarısında başlayan Sanayi Devrimi, makineleşme ve teknoloji alanında büyük gelişmelere neden olmuştur. Teknolojiye entegrasyonda en önde gelen alanlardan birisi sağlık endüstrisidir. Bu endüstri alanında hastalıkların teşhis ve tedavisini kolaylaştırmak, yanlış tanıyı önlemek için yapay zekâ yöntemleri ve güncel teknolojik yenilikler kullanılmaktadır. Yirmibirinci yüzyılda sağlık endüstrisinin, dördüncü sanayi devrimi ile bütünleşme gayreti içinde olduğu ve teknoloji kullanımına yoğunlaştığı görülmektedir. Sanayi devrimi ile hatasız üretimi amaçlayan yazılımlar geliştirilerek üretim ağı oluşturulmuş ve makinelerin çağı başlamıştır. Bu ilerlemelere paralel olarak tıp bilimi de teknolojiye entegre edilerek sağlık alanındaki dijital dönüşüm ortaya çıkmıştır. Sağlık alanındaki dijital dönüşümde en popüler olan konulardan biri Giyilebilir Teknolojilerdir (GT). Literatürde giyilebilir bilgisayarlar olarak da adlandırılan GT’ler, çeşitli şekillerde hastaların bedenine entegre olabilen araçlardır. Bu derlemede, GT’lerin, sağlık alanındaki uygulamalarını ortaya koymak, bunları cerrahi alan uygulamaları ve cerrahi hemşireliğine entegre etmek ve hastalara sunulan sağllk hizmetinin kalitesini arttırıcı önerilerde bulunmak amaçlanmıştır.
\end{abstract}

Anahtar Sözcükler: Giyilebilir teknoloji, cerrahi, hemşirelik bakımı, sağlık hizmetleri.

\section{Use of Wear Technology in the Field of Surgical Nursing}

\begin{abstract}
The Industrial Revolution, which started in England in the second half of the eighteenth century, led to great developments in the field of mechanization and technology. One of the leading areas in integration with technology is the healthcare industry. Artificial intelligence methods and current technological innovations are used in this industry to facilitate the diagnosis and treatment of diseases and to prevent misdiagnosis. It is seen that in the twenty-first century, the healthcare industry is in an effort to integrate with the fourth industrial revolution and concentrates on the use of technology. With the industrial revolution, software aimed at error-free production has been developed, a production network has been created and the age of machines has begun. In parallel with these advances, the digital transformation in the field of health has emerged by integrating medical science with technology. Wearable Technologies (GT) are one of the most popular topics in digital transformation in the field of health. Wearable technologies, also called wearable computers in the literature, are tools that can be integrated into the body of patients in various ways. In this review, it is aimed to reveal the applications of GTs in the field of health, to integrate them into surgical field practices and surgical nursing, and to make suggestions to increase the quality of health care provided to patients.
\end{abstract}

Keywords: Wearable technology, surgery, nursing care, healthcare.

Derleme Makale (Review Article)

Geliş / Received: 06.06.2021 \& Kabul / Accepted: 08.12.2021

DOI: https://doi.org/10.38079/igusabder.948675

* Yüksek Lisans Öğrencisi, Manisa Celal Bayar Üniversitesi Sağlık Bilimleri Enstitüsü, Hemşirelik Anabilim Dalı, Cerrahi

Hastalıkları Hemşireliği Tezli Yüksek Lisans Programı, Manisa, Türkiye, nergisk.falay6@gmail.com

ORCID https://orcid.org/o000-0002-5257-5872

** Prof. Dr., Manisa Celal Bayar Üniversitesi, Sağlık Bilimleri Fakültesi, Hemșirelik Bölümü, Cerrahi Hastalıkları

Hemşireliği AD, Manisa, Türkiye, E-posta: emelyilmazcbu@gmail.com ORCID http://orcid.org/o000-0002-5127-6651 


\section{Giriş}

Dünya Sağlık Örgütü (DSÖ) sağlık hizmetlerinde kullanılan teknolojiyi; yaşam kalitesini yükselten ve sağllk problemlerinin çözümü için geliştirilen yöntemler, sistemler, ilaçlar, aşılar, cihazlar tarafindan geliştirilen yetenek ve organize bilgilerin kullanılması olarak tanımlamaktadır. Teknolojiler, sağlık hizmetlerinin sunumu, bireylerin sağllğının sürdürülmesi, hastalıkların ortaya çıkmasının geciktirilmesi ya da engellenmesi ve sağlık sorunlarına çözüm bulmak amacı ile kullanılmaktadır². Sağlık hizmetleri 400 yıldır hastanelerde sunulmuş, daha sonra gelişmiş ülkelerde hastalar ihtiyaç duyulan alanlarda tedavi edilmeye başlanmıştır3. Sağllk hizmetlerinin hastane dışına genişletilmesi, hastaları daha geniş zaman aralıklarında izleyebilme olanağı sağlamıştır4. Bunun yanı sıra ülkemizde ve dünyadaki nüfus artışıyla beraber bireylerin hastenelerde uzun süre tedavi ve bakım hizmetlerini alması önemli ekonomik yüke neden olmaktadır. Hastanelerde uygulanan ve uzun süren tedaviler, kişilerde hastane yatışına bağlı olarak psikolojik, fiziksel ve sosyal sorunlara yol açabilmektedir5. Sağllk hizmetlerinde yaşanan gelişme ve değişimler, sağlık hizmetlerinin hastane dışında da verilebilmesi, kişilerin sağlık durumlarına yönelik daha fazla veri toplanmasını zorunlu hale getirmiştir. Bu amaçla giyilebilir teknolojilerden yararlanılmaktadır ${ }^{1,5,6}$.

Giyilebilir teknoloji (GT) ürünleri; sabit bir yere bağlı kalmadan, hareket halindeyken bilgiye ulaşmayı sağlamaktadır. Bu ürünler, kablosuz ve uzun süreli veri takibi sağlamak amacıyla akıllı telefon ya da bilgisayara senkronize edilmiş, elektronik özel izleme araçlarıdır. Bu araçlar sayesinde bireylerin sağlık durumuna ilişkin bilgiler uzaktan takip edilebilmekte, mekandan bağımsız olarak tıbbi veriler hekime gönderilebilmekte, ilaç kullanımı, diyet ve egzersiz programları hastane dışından sağlanabilmektedir7,8. Giyilebilir teknoloji araçları, bireyin alışkanlıkları, uyku saatleri ve süresi, ilaç saatleri, daha önceki hastalık hikayesi ve yapılan tanı testleri, tanı konulan hastalıklar, bireysel ölçüm uygulamarı, bireylerin diyeti, günlük adım sayısı, anksiyete düzeyi, vücut ağırlığı, kan glikoz düzeyi, kan basıncı, nabız sayısı ve oksijen saturasyonu gibi sağlı̆̆a ilişkin verileri kaydedebilmektedir ${ }^{1,6}$.

Kişisel giyilebilir cihazların kullanımı ile bireylerin sağlık hizmetlerindeki gelişmelerden daha fazla yararlanması (hastalıkların erken tanısı, izlemi, sağlıklı yaşam ve yaşam kalitesi) ve hastalara ilişkin verilere daha kolay erişim sağlanmıştır9,10. Giyilebilir teknolojiler, hastaların/bireylerin sağlık hizmetlerine hastane dışında da erişimine olanak sağlamıştır. Böylece hastalara/bireylere bir sağlık kuruluşuna başvurmadan genel sağlık durumları hakkında bilgi sahibi olma ve sağlık çalışanlarına da hastalarını geniş zaman aralıklarında izleyebilme şansı tanımaktadır ${ }^{1,8}$. Birleşik Devletler, halkın \%60'ının kilo, egzersiz ve diyet programlarını izlemekte ve \%33'ünün ise kan glikoz düzeyi, kan basıncı, uyku düzeni ve baş ağrısı gibi diğer parametrelere ilişkin ölçümlerini kaydederek bireysel ölçümde yeni bir akım oluşturmuştur. Bununla beraber bu ülkede internet kullananların \%27'si çevrimiçi olarak kendi sağlık verilerini izlemekte ve \%9'u sağllğa ilişkin uyarı mesajını kullanmaktadır. Ayrıca 40.00o sağlık uygulamasına akıllı telefonlar ile erişilebilmektedir 6 .

\section{Giyilebilir Teknolojinin Tanımı ve Önemi}

Giyilebilir teknoloji ya da giyilebilir cihazlar, vücuda rahatça takılan, kıyafet ve takılara entegre edilebilen elektronik alet ve bilgisayarlar olarak tanımlanmaktadır ${ }^{8}$. İnsanlar, bu teknoloji ile dâhili bellekleri olan cihazlar veya interneti kullanarak bilgiye anlık olarak erişebilmektedir ${ }^{11}$. Giyilebilir teknoloji, üste giyilen aletlerin genel adı olarak ifade edilmektedir. Bir ürünün giyilebilir teknoloji olması için, bu ürünün akıllı sensörler aracılığıyla gelen bilgileri bluetooth ya da kablosuz olarak akıllı telefona bağlanarak aktarması gerekir7. Giyilebilir cihazlar, hızla büyüyen ve gelecekte toplumsal etkileri de artacak teknolojik gelişmedir. Bu teknolojiler; verilerin 
toplanması, etkinliklerin izlenmesi, deneyimlerin kullanan kişilerin ihtiyaç ve isteklerine göre özelleşebilen ağa bağlı cihazlardır. Sensörler ve mikroçipler ile kablosuz iletişim sağlayan akıllı cihazlar bu grupta yer almaktadır ${ }^{12}$. Giyilebilir cihazlara gözlükler, saatler, akıllı kumaşlar, kontakt lensler, kasketler ve kapaklar, kafa bantları, bilezikler, abaküs yüzükler ve küpeler örnek olarak verilebilir. Ürünler, biyolojik geri bildirim, psikolojik durumları izleme, algılama gibi cep telefonlarında ve bilgisayarlarda görülemeyen birçok özelliğe de sahiptir ${ }^{11}$.

\section{Geçmişten Geleceğe Giyilebilir Teknoloji}

Giyilebilir teknolojinin tarihsel gelişimi, ilk olarak 17. yüzyılda Çin'de fasulye satılan yerlerde yazı materyali kullanmadan matematiksel işlemlerde bir abaküs halkasının kullanılması ile başlamıştır13. Bugünkü modern anlamda ilk giyilebilir bilgisayar, 1955 yılında Edward O. Thorp tarafından tasarlanmış ve 1961'de Claude Shannon'un desteği ile icat edilmiştir. Bu ilk giyilebilir cihaz, ayakkabı-tabanlı zamanlama cihazı olarak oyunlarda hile yapmak amacıyla kullanılmıştır ${ }^{14}$. Daha sonra 1975 yılında hesap makinesi olan dünyanın ilk kol saati piyasaya çıkarılmıştır. Collins 1977 yllında görme engelli bireyler için yeleğe monte edilen dokunmatik giyilebilir cihaz tasarlamıştır. Steve Mann tarafından 1981'de başa monte edilen birçok özelliği bulunan sırt çantasına benzer bilgisayar tasarlanmıştır7. Yang ve Rhee (2000), bireylerin sağlık durumlarını her zaman gözlemleyebilen, üzerine algılayıcı yerleştirilen bir yüzük tasarlamışlardır¹5.

Giansanti (2006), düşmeyi önlemek amacıyla kinematik algılayıcılar geliştirmiştir. Buna yönelik olarak tasarlanan giyilebilir bir klinik araç yardımıyla kinematik parametreler elde edilmiştir ${ }^{16}$. Başka bir çalışmada ise, giyilebilir sensör yamaların, cilt üzerine yapıştırıldığı, içinde sensörlerin yer aldığı ve düzenli şekilde verileri takip ettiği belirtilmiştir. Deri yamaları, belli zaman aralıklarında kullanılan, mobil uygulamalar ile verilerin aktarıldığı ve entegre çalışmaya olanak sağlayan kitlerdir 17-19. Nesnelerin interneti, geleneksel nesnelerin, çip ve sensörler, gömülü cihazlar, algılayıcı ağlar, haberleşme ve internet protokolleri uygulamaları gibi temel teknolojiler ile akıllı olanlara dönüşmesidir 5 . Nesnelerin interneti ile nesnelerin, cihazların ve makinelerin birbiri ile iletişimi sağlanmaktadır. Terden alkol muayenesi, kan glikoz takibi, stres ölçümü, vücut kitle indeksi ölçümü, idrarda tuz oranı, pH değeri gibi analizler, vücut sıcaklığı ölçümleri, laktat, glikoz, ürik asit, askorbik asit, $\mathrm{Na}^{+}$ve $\mathrm{K}^{+}$analizleri yapılmaktadır ${ }^{17-19}$. Deri yamasından yararlanılarak epidermal yolla tek doz grip aşısı uygulanmıştır²0. Basınç yaralarını önlemek için Leaf Patient Monitoring System (Leaf Hasta İzleme Sistemi) tasarlanmıştır. Basınç yaraları hastanın çok uzun süre hareketsiz kalmasından kaynaklanmaktadır. Bu sistemde, sensör takıldıktan sonra hastanın pozisyonu ve aktiviteleri izlenmektedir. Ayrıca sistem hastanın hareket etmesi gereken durumlarda, hastayı uyararak hangi pozisyonu alacağı ya da ne zaman hareket edeceğini kullanıcı arayüzünde göstermektedir. Bu sistem, çoğunlukla hastanelerde kullanılmakta ve hastanın doğru pozisyonu alması için hekim ya da hemşireye uyarı göndererek bilgilendirmektedir ${ }^{21}$. Riboni ve Bettini'nin (2011) çalışmasında, bisiklet sürme, diş firçalama, hafif tempoda koşma, gezinme, ayakta durma, tahtaya yazı yazma, merdiven inme ve çıma aktivitelerini saptamak için Android tabanlı akıllı telefondan elde edilen algılayıcı verileri kullanılmıştır ${ }^{22}$. Kırk yaşın üzerindeki erişkinlerin dörtte birinden fazlasını etkileyen atrial fibrilasyonu belirleyebilen, göğüs ya da parmaktan EKG kaydını yapabilen ve akıllı telefonlar ile uyumlu bir cihaz-sensör yaması kullanılmaktadır. Bu cihaz, FDA (Food and Drug Administration) onaylıdır ve AliveCor tarafından geliştirilmiştir. Hafif, ince ve esnek bir tasarıma sahip olan "VitalConnect", hasta cildine yapıştırılarak, montaj ve şarj ihtiyacı olmadan kullanılabilmektedir. Bu cihaz, 21 farklı kardiyak ritmi ve dört yaşam bulgusunu (tek uçlu EKG, nabız, solunum hızı ve vücut sicaklığı), tek bir kablosuz biyosensörde birleştirerek gerçek zamanlı olarak takip edip, sonuçları mobil cihazlarda gösterebilmektedir. Aynı zamanda VitalConnect, genişletilmiş holter olarakta kullanılmaktadır²3. Wang ve arkadaşları, kardiyovasküler sorunları daha erken ve duyarlı 
şekilde belirlemek için, küçük ve giyilebilir bir ultrasonografi (USG) yaması geliştirmişlerdir. Bu sayede, arteriyel kan basıncını izleyebilmişlerdir ${ }^{24}$. Gelişen teknoloji ile birlikte GT kullanımı artmıştır. International Data Corporation verilerine göre; 2018'de 172.2 milyon giyilebilir ünite sevk edilmiştir ${ }^{25}$. Gelecekte ise; genel kullanım için kumaşlardaki (Google'ın Proje Jakarlı) iyileştirmelerle birlikte GT, görünmez olacaktır. Günlük kullanımın ötesinde, nanoteknoloji (dahili olarak) ve biyo-hack uygulamaları (deri altında) gibi teknolojik gelişmeler sayesinde, implantlardan sensörlere kadar çok çeşitli alanlarda verimi arttıran bir kombinasyon oluşturulacağ 1 belirtilmektedir ${ }^{26}$. 2012 yllında FDA tarafindan onaylanan sindirilemeyen sensörler, yapılan tedavilerin organlar üzerindeki etkisine ilişkin bilgi vermektedir. Bakır ve magnezyum içeren geliştirilmiş sensörler, mide asidi ile etkileşime girdiğinde, EKG, solunum ve kalp hızı izleminde yararlanılmaktadır. Bu ürünler, oral yoldan kapsül ilaçlar gibi tüketilmektedir. $\mathrm{Bu}$ kapsül ile bireyin sağlı̆̆ına ilişkin bilgiler kaydedilip mobil uygulama cihazları ile izlenebilmektedir. Özellikle sindirilemeyen sensörlerin, hastalıkların erken tanısında çok etkili olacağl öngörülmektedir ${ }^{27}$. Bu teknoloji, sağllğa ilişkin parametrelerin (kan glikoz düzeyi, aktivite düzeyi vb.) sürekli izlenmesine olanak sağlamaktadır. Bu sayede elde edilen veriler, kişileri fiziksel durum ve diyet gereksinimlerine göre alışverişe yönlendirmede kullanılacaktır. Hekimler, bireylerin geçmiş dönemdeki davranışlarını ve yaşam tarzını ayrıntılı ve doğru bir şekilde görebilecektir. Giyilebilir teknoloji ürünleri, vücutta implantlar olarak ya da intradermal (ID) olarak da kullanılabilecektir28. Gelecekte, tüm tıbbi teknolojilerin daha akıllı, erişilebilir, küçük ve uygun maliyetli olacağı düşünülmektedir. Vancouver merkezli Clarius, bir Ios veya Android uygulamasını kullanarak, görüntüleri akıllı telefonlarda gösteren elde taşınabilir bir USG geliştirerek mobil USG de devrim yaratmıştır. Teknolojik gelişmeler devam ettikçe, maliyetlerin azalacağı ve bakım gerektiren her durumda erişilebilirliğin artacağı düşünülmektedir ${ }^{29}$.

\section{Giyilebilir Teknolojinin Hemşirelikte Kullanımı}

Son yıllarda, GT'ler pek çok alanda kullanılmaktadır. Tıp alanında, doğal afet ve yardım alanlarında, arama kurtarma çalışmalarında, acil servislerde, evde bakım uygulamaları ve eğlence sektörlerinde giyilebilir teknolojilerden yararlanılmaktadır. Sağlık alanında kolay kullanımı, verimi artırma ve zamandan tasarruf etme gibi avantajları nedeniyle çoğu biyolojik verinin ölçümünde kullanılmaktadır ${ }^{30}$. Çoğu insan, sosyal medya kaynakları ve çevrimiçi sağlık uygulamaları aracılığıyla kendi sağlık hizmetlerini yönetme becerisine daha çok katılmaktadır ${ }^{11}$. Sağlık alanında GT’nin geliştirilmesine yönelik ilginin iki temel nedeni vardır; birincisi GT'nin, verilerin uzun süreli izlemine olanak sağlayacağı ve böylece de hastalıkların tanı ve tedavisinde ilerleme kaydedilebileceği düşüncesidir. İkinci olarak ise, holter gibi cihazların bazı hastalıklarda oluşan durumları belirlemedeki yetersizliklerinin bu teknoloji sayesinde aşılacağı düşüncesidir32. Araştırma şirketleri, sağlık hizmetlerinde kullanılan giyilebilir cihaz pazarının artacağını belirtmektedir33.

Günümüzde insanların, daha fazla sağlıklarını önemsediği ve günlük yaşamlarında giyilebilir ürünler kullanmaya başladıkları görülmektedir. Giyilebilir sağlık teknolojisi, hekimler / hemşireler ile hastalar arasında sürekli iletişimi sağlayan büyük bir etkiye sahiptir. Hastalar, evlerinden ayrılmadan veya iş ortamlarında 24 saat boyunca sağlık durumlarını kontrol altında tutma ve hekimlerden gerçek zamanlı geri bildirim alma olanağına sahiptir. Bu durum, hastaların gereksiz yere hastaneye yatmalarını veya poliklinikleri sık sık ziyaret etmelerini önlemekte, stres düzeylerini ve sağlık giderlerini azaltmaktadır. Ayrıca bu cihazların, hekimlerin / hemşirelerin fazla zaman harcamadan hastayla iletişim kurmalarını sağlama gibi avantajları da bulunmaktadır. Bu teknoloji, kablosuz veri iletimi ve uyarı mekanizmalarının devreye girmesini sağlamaktadır. Böylece, hastalıklara neden olan risk ve tehlikeler oluşmadan önlemler alınabilmekte ve telafisi mümkün olmayan maddi ve manevi kayıplar azaltılabilmektedir33. 
Sağlık teknolojisindeki bu gelişmeler, hemşirelik bakımına olumlu katkılar sağlamaktadır34,35. Hemşirelik, bireyi tanıyıp anlayan, sağlığa ilişkin gereksinimlerini saptayan, gerekli olan bakımı ve eğitimi sağlayabilen bir meslektir33. Hemşirelik, yardım etme hedefine bakım verme ile ulaşan, sağlığa ilişkin gereksinimlerini saptayan, bakımı, bakım yönetimini, ölçme ve değerlendirmeyi sağlayabilen bir meslektir ${ }^{6}$. Dolayısıyla, profesyonel hemşirelik bakım uygulamalarında, sağlığın geliştirilmesi ve sürdürülmesinde bu teknolojik araçların geliştirilmesi ve uygulama sürecine katılması gereklidir. Bu teknolojik gelişmeler, bireylerin bakımına katılan herkese, bireyin bulgularına ilişkin sürekli izlem ve kayıt yapma olanağı sunmaktadır37. Böylece hastalarda morbidite ve mortalite azaltılarak, yaşam kaliteleri arttırılabilecektir34,35.

Literatürde hemşirelik hizmetlerinde GT’nin kullanımına ilişkin yapılan çalışmaların, hemşirelik bakım kalitesini artırmaya, hemşire kaynaklı hataları azaltmaya odaklandığı görülmektedir. Önlenebilir tıbbi hatalar, hastanelerde hasta ölümlerinin önde gelen nedenlerinden biridir. Bu olumsuz olaylar çoğunlukla, hemşirelerin sıklıkla bilişsel, algısal ve fiziksel aşırı yükler altında çalıştığı, yoğun bakım ünitelerinde (YBÜ) meydana gelmektedir. Bu aşırı yüklenmelere katkıda bulunan faktörlerden biri, tedavi planının, izleme bilgilerinin ve ekipman durumunun çok sayıda, mekansal olarak ayrılmış bilgi ekranında gösterilmesidir. Önce bu ayrı ekranlar yatak başında tek bir entegre ekran olarak birleştirilerek, hemşirelik iş yükü azaltılmış, hastanın tedavi planı ve fizyolojik durumu hakkında hemşirenin farkındalığı arttırılmıştır. Bu alanda geçtiğimiz 10 yılda yapılan en büyük teknolojik gelişmelerden biri hasta ile ilgili tüm verilerin aynı ekrana entegre edildiği bilgi işletim sistemleridir38. Bu gelişme ile birlikte hemşireler, yaşam bulgularının takip edildiği hasta izlem monitörleri, infüzyon pompaları ve ilaç takip planlarını tek ekranda görme imkanına kavuşmuştur. Bu entegre sistem, hasta bakım kalitesini anlamlı olarak artırmış ve özellikle YBÜ'de günlük pratiğe girmiştir. Teknolojinin hızlı ilerlemesi ile birlikte bu yeniliklerde daha da ileriye gidilerek sabit, hantal ekranlardan giyilebilir, portatif sistemlere geçilmiştir. Utah Üniversitesi Hemşirelik Yüksekokulu'nda, hemşirelerin koluna takılabilen akıllı saatler geliştirilmiş ve 20 yataklı hasta simülasyon ünitesinde tam ölçekli bir YBÜ hazırlanarak, bir klinik deney gerçekleştirilmiştir. Deney sırasında hemşireler, alarm durumunda bileklerindeki akıllı saatte kısa, rahatsız edici olmayan bir titreşim yoluyla uyarılmıştır. Bu akıllı saatler; infüzyon pompaları, kalp hızı, kan basıncı, solunum hızı ve oksijen saturasyonunun ölçüldüğü hasta monitörlerine ve çağrı ışı̆̆ı sistemlerine entegre edilmiştir. Entegrasyon sonrası hemşire yanıt süresinde iki buçuk kat iyileşme elde edilmiş ve bu sonuç istatistiksel olarak da anlamlı bulunmuştur. Askeri savaş sistemlerinde kanıtlanmış bu yenilikçi alarm yöntemleri, hemşirelerin mevcut alarm/uyarı sinyallerini daha kolay algılamasına yardımcı olmuş ve hasta güvenliğini önemli ölçüde iyileştirebilme olasılığını ortaya koymuştur39.

\section{Cerrahi Hemşireliği Alanında Giyilebilir Teknoloji Kullanımı}

Cerrahi işlemler, vücuttaki bir hasarı onarmak veya bir hastalığı durdurmak için gerçekleştirilen tıbbi işlemler olarak tanımlanmaktadır ${ }^{40}$. Giyilebilir teknolojinin sağlık alanında yaygınlaşmasına paralel olarak cerrahide de kullanımı giderek artmaktadır. Literatürde sunulan güncel verilerde buna bağlı olarak artmaktadır. Cerrahide GT'den, birçok farklı cerrahi alanda hastalıkların tanılanmasında, ameliyat sonrası hastaların değerlendirilmesi ve izleminde yararlanılmaktadır. Ayrıca bu teknoloji, farklı uygulamaların birbiriyle karşılaştırılmasında, fiziksel aktivitenin ölçümünde ve cerrahi eğitimin bir parçası olarak da kullanılmaktadır. Steril bir ortamda çalışan cerrahların ve hemşirelerin gereksinimleri doğrultusunda ameliyathanede de GT'den yararlanılmaktadır41,42. Hastalarda ameliyat sonrası fiziksel aktivitenin ölçümü, giyilebilir teknolojilerin cerrahi hastalarında kullanımına örnek olarak verilebilir. Cerrahi sonrası kanser hastalarında sıklıkla fiziksel aktivitede azalma gözlenir. Bu durum, ameliyat sonrası kötü sonuçlara ve kanserin erken nüks etmesine neden olmaktadır. Jin-Ming Wu ve ark. (2019), 
gastrik kanser cerrahisi sonrası hastaların fiziksel aktivite oranını değerlendirmek için fiziksel aktiviteyi kaydeden giyilebilir cihazlar kullanmış ve ameliyattan sonra taburcu olacak hastaları eğiterek, yürüme adımlarını otomatik olarak kaydetmişlerdir. Hastalar ameliyat sonrası 28. güne kadar veri aktarmaya devam etmiş ve toplanan veriler bu sistemin uygulanabilir olduğunu göstermiştir. Gastrik kanser cerrahisi sonrası hastalarda giyilebilir cihazlarla cep telefonu uygulamalarının fiziksel aktiviteyi objektif olarak değerlendirmede yararlı olduğu belirtilmiştir43.

Farklı tedavi yöntemlerinin karşılaştırılması da GT’nin kullanıldığı diğer bir alandır. Isabeau Thijs ve ark. (2019), kalp cerrahisi sonrası rehabilitasyonda GT ile fiziksel aktiviteyi değerlendirdikleri prospektif gözlemsel bir kohort çalışması yapmışlardır. Çalışmada, konvansiyonel pompa dışı koroner arter bypass (OPCAB) ile robotik destekli minimal invaziv koroner arter bypass (RAMIDCAB) ameliyatı geçiren hastalarda, giyilebilir fitness izleyicileri kullanarak kardiyak rehabilitasyondaki fiziksel aktiviteyi karşılaştırmışlardır. Giyilebilir teknoloji kullanılarak yapılan bu çalışmada, taburcu olduktan sonraki ilk haftalarda fiziksel aktivitenin RA-MIDCAB hastalarında daha iyi olduğu belirlenmiştir44. Belçika'da kalp damar cerrahları ve kardiyologların yaptığı bir sistematik derlemede, Lomber Spinal Stenoz (LSS) hastalarının objektif yürüyüş ölçümü için giyilebilir cihazların doğruluğu ve güvenilirliği değerlendirilmiştir. Giyilebilir cihazlarla yürüyüş döngüsü, adım uzunluğu, yürüyüş hızı ve adım sayısı ölçümleri değerlendirilmiştir. Giyilebilir cihazlar, LSS hastalarının yürüyüş ölçümünde objektif sonuçlarla kullanılabilir bulunmuştur. Bununla birlikte, veri ve analiz sınırlılığ nedeniyle cihazların güvenilirliği hakkında yorum yapmak için daha fazla çalışma önerilmiştir45.

Beyin cerrahisi kliniğinde takip edilen hastaların omurga postürünü izleyen giyilebilir cihazları spesifik olarak inceleyen Simpson ve ark. (2019), günümüzde mevcut olan cihazların klinik ortamda, spinal postürü değerlendirmede doğruluk düzeyinin iyi olduğunu bildirmiştir. Bununla birlikte, bu teknolojilerin uzun süreli kullanımı ile ilgili daha fazla doğrulama ve pratiklik ile ilgili iyileştirmeler önerilmiştir46.

Giyilebilir teknolojiler cerrahide sadece ameliyat sonrasında değil, ameliyat öncesi dönemde de kullanılmaktadır. Traci ve arkadaşlarının (2020) çalışmasında, giyilebilir aktivite izleme cihazlarının kullanımı konusunda hastalara eğitim verilerek, ameliyattan önce 30 gün boyunca cihazı takmaları söylenmiş ve giyilebilir cihazlarla hastaların adım sayıları kaydedilmiştir. Çalışma sonucunda; cihazlara kaydedilen veriler incelenmiş ve verilen programa uyarak daha çok mobilize olan hastalarda ameliyat sonrası komplikasyon oranında anlamlı bir düşüş sağlandığı görülmüştür47.

Ameliyat öncesi aktivitenin ameliyat sonrası sonuçlara etkisini değerlendirmek amacıyla yapılan çalışmada, kolorektal cerrahi öncesi 99 hastada GT kullanılmıştır. Hastalara bu cihazlarla ilgili geniş kapsamlı bir eğitim verilmiş, ameliyattan 30 gün önce bu cihazlar hastalara takılıp, ameliyat sonrası komplikasyon oranları karşlaştırılmıştır. Araştırma sonucunda, kolorektal cerrahi geçiren hastaların ameliyat öncesi dönemdeki aktivite seviyelerinin iyileşme için önemli olduğu ve yetersiz aktivitenin komplikasyon oranını artırdığı ifade edilmiştir. Ayrıca, GT ile elde edilen bu verilerin ameliyat sonrası iyileşmeye yardımcı olup olmadığını araştıran girişimsel bir deneme için temel oluşturacağ belirtilmiştir47.

Giyilebilir teknolojiler, transplantasyon cerrahisinde de kullanılmaktadır. Daha yaratıcı teknolojiler, cerrahi işlem ile insan vücuduna implante edilebilmektedir. Salani ve arkadaşları (2018), GT'den yararlanarak ürettikleri transplante edilebilir yapay böbreklerin diyaliz tedavisine olan ihtiyacı azaltarak, renal replasman tedavisini daha erişilebilir ve istenilebilir hale getireceğini, personel ihtiyacını ve sağlık bakım maliyetlerini düşürebileceğini belirtmişlerdir. Ancak klinik uygulamadan önce ek çalışmaların yapılmasını önermişlerdir ${ }^{4}$. Giyilebilir 
teknolojiler ile ilgili bu umut verici sonuçlara rağmen aksi yönde bulgular da mevcuttur. Örneğin, Periferik Arter Hastalığı (PAH) olan bireylerde, giyilebilir aktivite izlemi ve telefon koçluğundan oluşan evde yapılan bir egzersiz müdahalesinin değerlendirildiği bir çalışma yapılmıştır. Egzersiz müdahalesinin, normal hasta bakımına kıyasla, dokuz aylık takipte yürüme performansını iyileştirmediği bulunmuştur. Bu sonuçlar, $\mathrm{PAH}$ 'lı hastalarda yürüme performansını iyileştirmek için periyodik hasta başı ziyaretler olmadan, giyilebilir cihazların ve telefon danışmanlığının ev tabanlı egzersiz müdahalelerinde yetersiz olduğunu göstermektedir. Bu alanda ek çalışmalar önerilmiştir49.

Giyilebilir teknolojiler cerrahi eğitiminde, ameliyat sunumunda, çeşitli kurslarda ve online platformlarda öğrenciler ve eğitimciler tarafından kullanılmaktadır. Steril ortamlarda kullanım için geliştirilmiş, cerrahın perspektifinden canlı olarak cerrahi işlemlerin gösterilmesi için başa takılan kameralar örnek olarak verilebilir5․ Tüm bu olumlu gelişmelerin yanında sağlıkta GT’nin kullanımı teknolojik yeniliklere rağmen, giyilebilir cihazların yaygın olarak benimsenmemesi, literatürün henüz kısıtlı olması, güvenlik endişesi ve maliyet etkinliği gibi nedenlerle hala son derece kısıtlıdır. Ocak 2010'dan Şubat 2019'a kadar sağlık hizmetlerinde GT ile ilgili bilimsel literatürün incelendiği sistematik bir derlemede, kullanıcıların, teknoloji kabulü, güvenlik, gizlilik ve emniyet gibi konularda kaygı duydukları belirtilmiştir. Bu derlemede, pil teknolojisi ve enerji verimi için etkili çözümler üzerine araştırmaların gecikmesi, giyilebilir çözümler tasarlamanın önündeki en büyük engellerden biri olarak gösterilmiştir. Bununla birlikte, güvenilirlik ve konfor düzeylerini geliştirmek için daha fazla araştırma gerektiği bildirilmiştir ${ }^{1}$.

Giyilebilir teknolojilerin kullanıldığı başa takılan kameralar ile aseptik koşulların sağlandığı ameliyathanelerde, güvenli bir eğitim ortamı oluşturulmaktadır. Üçüncü kişiler tarafından videoların görüntüleme cihazları ile kaydedilmesine gerek duyulmadan, hem sterilite korunmakta hem de ameliyat direkt uygulayıcısının gözünden birçok cerraha yansıtılmaktadır. Gelecekte bu şekilde, tek bir eğitimcinin gözünden aynı anda kişi sınırlaması olmadan verilen eğitimin, sadece cerrahlar için değil, hemşirelik öğrencileri için de aktif olarak kullanılması eğitimde önemli bir rol oynayabilir. Ameliyathane hemşiresi tarafından başa takılan kamera ile duygu durum, deneyimler, ameliyat süreci ve cerrahi stresin yansitılması ameliyathane hemşirelerinin eğitiminde de kullanılabilir. Cerrahlar ve hemşireler GT’nin sağlık ve cerrahi alanında kullanımının devrim yaratacağını düşünmektedir.

\section{Sonuç ve Öneriler}

Nüfus artışı, bilim ve teknolojideki gelişmeler ve bireylerin ihtiyaçlarının değişmesi ile beraber sağlık bakım sistemindeki değişimler hızlanmıştır. Bu değişim ve gelişmeler, tüm profesyonel mesleklerdeki gibi tıp ve hemşirelik alanını da etkilemektedir. Hemşireler sağlık sisteminde bakım hizmeti vermektedir. Verilen bakımın değerlendirilmesi, iyileştirilmesi, etkin ve kaliteli olması önemlidir. Tüm bunların yerine getirilebilmesi için hemşirelerin yenilikleri takip etmesi ve yenilikci, uygulamalara uyum sağlaması gereklidir. Gelecek yıllarda hemşireler bilişim teknolojisindeki bilgi ve becerileri, sağllk bakım uygulamalarında kullanarak yeni rollere sahip olabilecektir. Gelişen teknolojiler ile bakım kalitesi ve hasta güvenliğinin arttırılabilmesi için klinik kararlar, doğru ve güncel bilgilerle desteklenmelidir.

Cerrahi alanında bu tür teknolojilerin geliştirilmesi ve yapay zekanın uygulamaya konulmasının tıbbi hata oranını düşüreceği, sağlık profesyonellerinin verimliliğini artıracağ ve ameliyatların sonuçlarını olumlu yönde etkileyeceği düşünülmektedir. Bu süreçte teknolojiyi geliştiren, uygulayan ve uygulanan arasında tam bir işbirliği gereklidir. Kliniklerde GT'ye olan eğilimler desteklenmeli ve arttırılmalıdır. Pratik uygulamada daha çok bilimsel çalışmaya ihtiyaç duyulmaktadır. 


\section{KAYNAKLAR}

1. Demirci Ş. Giyilebilir teknolojilerin sağlık hizmetlerine ve sağlık hizmet kullanıcılarına etkileri. Anemon Muş Alparslan Üniversitesi Sosyal Bilimler Dergisi. 2018;6(6):985-92.

2. National Center for Health Statistics (US). Health, United States, 2009: With Special Feature on Medical Technology. Hyattsville (MD): National Center for Health Statistics (US); 2010.

3. Barnard R, Shea JT. How wearable technologies will impact the future of health care. In: Lymberis A, Rossi D, editors. Wearable Health Systems for Personalised Health Management. Amsterdam: IOS Press; 2004: 49-55.

4. Aydan S, Aydan M. Sağlık hizmetlerinde bireysel ölçüm ve giyilebilir teknoloji: Olası katkıları, güncel durum ve öneriler. Hacettepe Sağllk İdaresi Dergisi. 2016;19(3):325-342.

5. Bodur G. Sağlık bakım sisteminde nesnelerin interneti (IoT): Geleceğe hazır mıyı? Archives of Health Science and Research. 2020;7(1):75-81.

6. Swan M. The quantified self: Fundamental disruption in big data science and biological discovery. Big Data. 2013;1(2):85-99.

7. Özgüner Kılıç H. Giyilebilir teknoloji ürünleri pazarı ve kullanım alanları. Aksaray Üniversitesi İktisadi ve İdari Bilimler Fakültesi Dergisi. 2017;9(4):99-112.

8. Lymberis A, Gatzoulis L. Wearable health systems: From smart technologies to real applications. IEEE Engineering in Medicine and Biology Society Annual Conference. 2006;Suppl:6789-92.

9. Lymberis A, Dittmar A. Advanced wearable health systems and applications. IEEE Engineering in Medicine and Biology Magazin: The Quarterly Magazine of the Engineering in Medicine \& Biology Society. 2007;26(3):29-33.

10. Deloitte. Healthcare and Life Sciences Predictions 2020. London: The Creative Studio at Deloitte; 2014.

11. Tehrani K, Andrew M. Wearable technology and wearable devices: Everything you need to know. Wearable Devices. http://www.wearabledevices.com/what-is-a-wearable-device/. Yayınlanma tarihi 2014. Erişim tarihi 25 Mayıs 2020.

12. Thierer A. The internet of things and wearable technology: Addressing privacy and security concerns without derailing innovation. Richmond Journal of Law \& Technology. 2015;21(6):1-118.

13. Page T. Barrierstothe adoption of wearable technology. Journal on Information Technology. 2015;4(3):1-15.

14. Thorp EO. The invention of the first wearable computer. Wearable Computers, Digest of Papers. In: Second International Symposium on wearable computers; Oct 19-20, 1998;4-8; Pittsburgh, PA, USA.

15. Yang BH, Rhee S. Development of the ring sensor for healthcare automation. Robotics and Autonomous Systems. 2000;30(3):273-81.

16. Giansanti D. Investigation of fall-risk using a wearable device with accelerometers and rate gyroscopes. Physiological Measurement. 2006;27(11):1081-90. 
17. Büyükgöze S. Giyilebilir teknolojilerden sağlık alanındaki sensör yamalar üzerine bir inceleme. Avrupa Bilim ve Teknoloji Dergisi. 2019;17:1239-47.

18. GETürkiyeBlog. GE’nin yeni bir giyilebilir teknoloji cihazı: ter yaması. GETürkiyeBlog. https://geturkiyeblog.com/genin-yeni-bir-giyilebilir-teknoloji-cihazi-ter-yamasi/. Yayınlanma tarihi Kasım 2019.

19. He W, Wang $\mathrm{C}$, Wang $\mathrm{H}$, et al. Integrated textile sensor patch for real-time and multiplex sweat analysis. Science Advances. 2019;5(11):eaaxo649.

20. Steafel E. From the flu jab to the pill - why microneedle patches are the future of Medicine. Telegraph. https://www.telegraph.co.uk/women/life/flu-jab-pill-microneedle-patchesfuture-medicineYayınlanma tarihi 2019. Erişim tarihi 24 Mayıs 2020.

21. Sullivan F. 2016 North American Pressure Ulcer Prevention New Product Innovation Award. Frost. https://ww2.frost.com/files/6514/5858/2856/Leaf Healt hcare Award Write Up.pdf. Yayınlanma tarihi 2016. Erişim tarihi 21 Mayıs 2020.

22. Riboni D. Bettini C. COSAR: Hybrid reasoning for context-aware activity recognition. Personal and Ubiquitous Computing. 2011;15(3):271-289.

23. Catlabdigest. Vital Connect HealthPatch MD Biosensor Receives FDA Clearance. Catlabdigest. https://www.cathlabdigest.com/article/Vital-Connect-HealthPatch-MDBiosensor-Receives-FDA-Clearance. Yayınlanma tarihi 2014. Erişim tarihi 20 Mayıs 2020.

24. Wang $\mathrm{C}, \mathrm{Li} \mathrm{X}, \mathrm{Hu} \mathrm{H}$, et al. Monitoring of the central blood pressure waveform via a conformal ultrasonic device. Nature Biomedical Engineering. 2018;2(9):687-695.

25. Framingham M. IDC reports strong growth in the worldwide wearables market, led by holiday shipments of smartwatches, wrist bands and ear-worn devices. IDC. https://www.idc.com/getdoc.jsp?containerId=prUS44901819 webcite. Yayınlanma tarihi 2019. Erişim tarihi 16 Nisan 2020.

26. Armstrong P. What's the future of wearable tech? Future of everything. http://www.futureofeverything.io/future-wearable-tech. Yayınlanma tarihi 2018. Erişim tarihi 28 Mayıs 2020.

27. Cat W. This digital pill wants to make following your prescription easier. PBS. https://www.pbs.org/newshour/science/following-a-prescription-is-hard-this-digital-pillwants-to-help. Yayınlanma tarihi 2018. Erişim tarihi 17 Mayıs 2020.

28. Hall L. What's the future of wearable tech? Future of everything. http://www.futureofeverything.io/future-wearable-tech. Yayınlanma tarihi 2018. Erişim tarihi 25 Mayıs 2020.

29. Batke K. What's the future of wearable tech? Future of everything. http://www.futureofeverything.io/future-wearable-tech. Yayınlanma tarihi 2018. Erişim tarihi 26 Nisan 2020.

30. Chan M, Estève D, Fourniols JY, Escriba C, Campo E. Smart wearable systems: Current status and future challenges. Artificial Intelligence in Medicine. 2012;56(3):137-156.

31. Sarasohn-Kahn J. A role for patients: The argument for self-care. American Journal of Preventive Medicine. 2013;44(1 Suppl 1):16-18.

32. Bonato P. Advances in wearable technology and its medical applications. IEEE Engineering 
in Medicine and Biology Society. Annual International Conference. 2010;2010:2021-2024.

33. Solutions S. 2013-2018 arası tele sağlık hastalarının sayısı. SaM Solutions.

https://www.sam-solutions.com. Yayınlanma tarihi 2019. Erişim tarihi 27 Mayıs 2020.

34. Parkı S. Jayaraman S. Enhancing the quality of life through wearable technology. IEEE Engineering in Medicine and Biology Magazine: the Quarterly Magazine of the Engineering in Medicine \& Biology Society. 2003;22(3):41-48.

35. Burrus D. The internet of things is far bigger than anyone realizes, wired. Wired. http://www.wired.com/insights/2014/11/the-internet-of-thingsbigger. Yayınlanma tarihi 2014. Erişim tarihi 6 Mayıs 2020.

36. Toru F. Hemşirelik uygulamalarının kilit noktası: Bireyselleştirilmiş bakım. Adnan Menderes Üniversitesi Sağlık Bilimleri Fakültesi Dergisi. 2020;4(1):46-59.

37. Wilson D. An overview of the application of wearable technology to nursing practice. Nursing Forum. 2017;52(2):124-132.

38. Koch SH, Staggers N, Weir C, Agutter J, Liu D, Westenskow DR. Integrated information displays for icu nurses: field observations, display design, and display evaluation.

Proceedings of the Human Factors and Ergonomics Society Annual Meeting. 2010;54(12):932-6.

39. McFarlane DC, Doig AK, Agutter JA, Bira LM, Syroid ND, Mittu R. Faster clinical response to the onset of adverse events: A wearable metacognitive attention aid for nurse triage of clinical alarms. PLoS One. 2018;13(5):e0197157.

40. Karadayı M, Yılmaz B, Erol B, Tozan H. Sağlık teknolojisi değerlendirmede çok kriterli karar verme yaklaşımları üzerine bir derleme çalışması. Düzce Üniversitesi Bilim ve Teknoloji Dergisi. 2020;8:264-269.

41. Lee SM. Google glass offers health care advantages, drawbacks. SFGATE. http://www.sfgate.com/technology/article/Google-Glass-offers-health-care-advantages5408266.php. Yayınlanma tarihi 2014. Erişim tarihi 9 Mayıs 2020.

42. Miller CC. At Google, bid to put its glasses to work. New York Times. https://www.nytimes.com/2014/04/o8/technology/google-begins-a-push-to-take-glassto-work.html. Yayınlanma tarihi 2014. Erişim tarihi 11 Mayıs 2020.

43. Wu JM, Ho TW, Chang YT, et al. Wearable-based mobile health app in gastric cancer patients for postoperative physical activity monitoring: Focus group study. JMIR Mhealth Uhealth. 2019;7(4): e11989.

44. Thijs I, Fresiello L, Oosterlinck W, Sinnaeve P, Rega F. Assessment of physical activity by wearable technology during rehabilitation after cardiac surgery: Explorative prospective monocentric observational cohort study. JMIR Mhealth Uhealth. 2019;7(1):e9865.

45. Chakravorty A, Mobbs RJ, Anderson DB, et al. The role of wearable devices and objective gait analysis for the assessment and monitoring of patients with lumbar spinal stenosis: systematic review. BMC Musculoskeletal Disorders. 2019;20(1):288.

46. Simpson L, Maharaj MM, Mobbs RJ. The role of wearables in spinal posture analysis: A systematic review. BMC Musculoskeletal Disorders 2019;20(1):55.

47. Hedrick TL, Hassinger TE, Myers E, et al. Wearable technology in the perioperative period: 
Predicting risk of postoperative complications in patients undergoing elective colorectal surgery. Diseases of the Colon and Rectum. 2020;63(4):538-544.

48. Salani M, Roy S, Fissell WH 4th. Innovations in wearable and implantable artificial kidneys. American Journal of Kidney Diseases: The Official Journal of the National Kidney Foundation. 2018;72(5):745-751.

49. McDermott MM, Spring B, Berger JS, et al. Effect of a home-based exercise intervention of wearable technology and telephone coaching on walking performance in peripheral artery disease: The HONOR randomized clinical trial. JAMA. 2018;319(16):1665-1676.

50. Slade Shantz JA, Veillette CJH. The application of wearable technology in surgery: Ensuring the positive impact of the wearable revolution on surgical patients. Frontiers in Surgery. 2014;1:39.

51. Loncar Turukalo T, Zdravevski E, Machado da Silva J, Chouvarda I, Trajkovik V. Literature on wearable technology for connected health: scoping review of research trends, advances, and barriers. Journal of Medical Internet Research. 2019;21(9):e14017. 